\title{
América Latina y América del Norte ante los procesos de regionalización mundial $^{*}$
}

\section{Pedro Manuel Rodríguez Suárez}

\section{RESUMEN}

Sin lugar a dudas, al terminar la Guerra Fría los regionalismos se expandieron en el escenario internacional, debido al fin de la confrontación ideológica Este-Oeste; a las transformaciones democráticas que tuvieron efecto en África, América, Asia y Europa; a las nuevas problemáticas transfronterizas que afectan a las regiones en el marco del siglo xxi, y al fenómeno de la globalización. Este artículo tiene tres objetivos cardinales. El primero, evalúa las variables sine qua non que han tenido un peso determinante a la luz de la edificación de las integraciones regionales durante la primera y la segunda ola. El segundo, pretende encontrar respuestas epistemológicas en relación con el éxito o el fracaso de los regionalismos, y el tercer y el último objetivo analiza el surgimiento y la evolución de los regionalismos en América Latina y en América del Norte. En este mismo orden de ideas, se analizan los resultados que han cosechado las integraciones regionales en ambas regiones de América, así como las mayores problemáticas que enfrentan. Con la finalidad de comprender teóricamente lo expuesto en este artículo se utilizará la teoría de juegos de Karl W. Deutsch, la teoría neoinstitucional de Sven Steinmo, así como la teoría de la seguridad compleja de Barry Buzan. Cabe hacer alusión a que el autor aplicará el marco teórico anteriormente mencionado en las conclusiones generales de este artículo.

* Este artículo es producto de la investigación financiada por la Vicerrectoría de Investigación y Estudios de Posgrado de la BUAP para Investigadores Consolidados durante el 2015.

** Doctor en Estudios de Integración Europea por la Universidad de Varsovia (Polonia). Especialista en Estudios Europeos por el IтAM; Profesor-investigador, Benemérita Universidad Autónoma de Puebla (BUAP), Puebla (México).pedrosuarezbuap@yahoo.com.mx

Recibido: 17 de noviembre de 2015/ Modificado: 12 de marzo de 2016/ Aceptado: 23 de junio de 2016

Rodríguez Suárez, P. M. (2016). América Latina y América del Norte ante los procesos de regionalización mundial. OASIS, 24, 27-44.

DOI: http://dx.doi.org/10.18601/16577558.n24.03 
Palabras clave: regionalismos, cooperación interregional, nuevo orden internacional, integraciones regionales y seguridad compleja.

\section{Latin American and North America before the world's regionalization process}

\section{ABSTRACT}

Undoubtedly, regionalism expanded in the international arena at the end of the Cold War. This was due to the end of the East-West ideological confrontation, democratic changes that took place in Africa, America, Asia and Europe, new cross-border conflicts which hamper the security of the regions, as well as the phenomenon of globalization. In this context, the subject of regionalism constitutes one of the most important issues within the international agenda of the XxI century. This article has three main objectives. The first evaluates the variables sine qua non, which have played a primary role in light of the construction of regional integration during the first and second age of regional integrations. The second aims to find epistemological answers regarding the success or failure of regionalism. The third and last goal is to assess the emergence and evolution of regionalism in Latin America and North America. Likewise, the author analyses the results that regional integration has achieved in both regions of America (South and North), as well as the key problems which regional integration in Latin America and North America face. In order to understand the aforementioned phenomena this article is based on Karl W. Deutsch's game theory, the neo-institutional theory of Sven Steinmo and in the theory of complex security of Barry Buzan. It should be noted that the aforementioned theories of international relations are applied in the conclusion of this article.

Keywords: Intraregional cooperation, new international order, regional integration and regional security.

\section{INTRODUCCIÓN}

La primera ola de regionalismos ${ }^{1}$ surgió durante las décadas de los cincuenta y setenta del siglo xx, y estuvo fuertemente influenciada por tres variables sustanciales. La primera, por la lucha ideológica que mantuvieron Estados Unidos y la otrora Unión de Repúblicas Socialistas Soviéticas (URSs) por casi medio siglo. La segunda, porque connotó la reacción explícita de algunos Estados de la comunidad internacional vis-á-vis la subscripción del Tratado de Roma en 1957, firmado por Bélgica, Francia, Italia, Luxemburgo, los Países Bajos y la República Federal de Alemania. En este tenor, algunos Estados de la comunidad internacio-

\footnotetext{
1 La terminología "regionalismos" se emplea en oposición al concepto de globalización y se refiere a un mundo que está menos interconectado, con un mayor énfasis en lo regional, así como a la integración económica y a veces política de los Estados que por lo general comparten un espacio geográfico determinado, aunque no siempre es así el caso.
} 
nal consideraron que las entonces Comunidades Económicas Europeas (CEE) protegerían el mercado europeo y, por consiguiente, sus exportaciones perderían competitividad; por tal motivo promovieron la integración económica dentro de sus propias regiones. La tercera representó la convicción que tuvieron algunos Estados emergentes, en particular de América Latina y África, inherente a que las integraciones regionales promoverían el desarrollo económico e industrial y terminarían con la dependencia histórica entre el centro y la periferia. Cabe mencionar que tanto los regionalismos que nacieron como respuesta a la integración europea, así como los latinoamericanos y africanos, no fueron creados con la finalidad de participar en el conflicto ideológico Este-Oeste.

La segunda ola de regionalismos que emergió a finales del siglo xx, particularmente en las décadas de los ochenta y noventa, continúa proliferando en pleno siglo XXI. Los regionalismos de la segunda ola emergieron en gran medida debido a las transformaciones radicales que tuvieron efecto en el escenario internacional al finalizar el siglo xx. En este marco de ideas, el fin de la Guerra Fría, el fenómeno de la globalización, el reconocimiento de los Estados en torno a las nuevas amenazas hacia su seguridad de carácter transfronterizo, así como el fin de los sistemas políticos autoritarios y totalitarios en América, África, Asia y Europa del Este, constituyeron fuertes catalizadores vis-á-vis las integraciones intrarregionales.

Por otro lado, la segunda ola de regionalismos demuestra la convicción empírica que tienen actualmente los Estados en relación con su "capacidad limitada" en aras de satisfacer sus necesidades, responder a los desafíos económicos y políticos internacionales, proyectar sus intereses ante la comunidad internacional, encontrar soluciones a los problemas transfronterizos, así como para incrementar su competitividad $v i s-\grave{a}$-vis a otras regiones del mundo. Sin lugar a dudas, la prioridad actual de la gran mayoría de los Estados de la comunidad internacional es la de buscar nuevas formas de cooperación desde un punto de vista cuantitativo y cualitativo, y, en particular, desde el ámbito regional. Este fenómeno ha sido conceptualizado por algunos estudiosos de las relaciones internacionales como María Paz (2011) como "la regionalización mundial".

Los regionalismos de la segunda ola connotan la antítesis de la autarquía y del unilateralismo, debido a que incorporan entre sus más altas prioridades la promoción de la cooperación intrarregional en detrimento de las acciones unilaterales. El regionalismo puede ser definido como una forma de cooperación internacional "intermedia” que se establece por medio de la creación de alianzas y de la cooperación entre Estados que, por lo general, comparten un espacio geográfico determinado. Aunado a lo anterior, puede ser entendido como un fenómeno no exclusivo del Estado debido a que la sociedad civil y la iniciativa privada (IP) participan en la edificación y en la evolución de las integraciones regionales (al menos en las sociedades occidentales). Asimismo, los regionalismos se fundamentan en valores, en un sentido de pertenencia regional e intereses compartidos, así como en el gran deseo por obtener "beneficios y ganancias compartidas" (Halizak, 1996, pp. 234-238). 
Este artículo tiene tres objetivos cardinales. El primero, evalúa las variables sine quan non que fueron determinantes en relación con la edificación de los regionalismos de la primera y segunda ola. El segundo, pretende encontrar respuestas teóricas y epistemológicas en relación con el éxito o el fracaso de los regionalismos, y el tercer y último objetivo, evalúa el surgimiento y la evolución de las integraciones regionales en América Latina y en América del Norte. Aunado a lo anterior, analiza los resultados de las integraciones regionales en ambas regiones de América y las problemáticas más importantes que enfrentan. Para tal efecto, se utilizará la teoría de juegos de Karl W. Deutsch, la teoría neoinstitucional de Sven Steinmo, así como la teoría de la seguridad compleja de Barry Buzan. Cabe hacer alusión a que el autor aplicará el marco teórico anteriormente mencionado en las conclusiones generales de este artículo.

\section{CONTRIBUCIONES TEÓRICAS DE CARA A LA REGIONALIZACIÓN MUNDIAL}

La teoría de juegos que sustenta Karl. W Deutsch alude al juego de suma variable y al juego de suma cero. En el juego de suma variable, los Estados que han decidido establecer una integración regional incorporan reglas muy claras e institucionalizan sus relaciones en aras de obtener beneficios mutuos y equitativos (Deutsch, 1994, pp. 32-40). Por el contrario, en el juego de suma cero uno o dos países obtienen los mejores resultados de la integración regional, en detrimento de los "países menos desarrollados". El juego de suma cero se presenta frecuentemente en los regionalismos que poseen poco nivel de integración, de cooperación, y, sobre todo, una endeble institucionalización, como es el caso de de los tratados de libre comercio (TLC). En los TLC no existe una cooperación muy profunda, ni tampoco hay mecanismo alguno que promueva la cohesión social y económica entre los actores involucrados.

Para la teoría neoinstitucional que plantea Sven Steinmo (2009, p. 45), las instituciones son fundamentales a fin de garantizar la "buen gobernanza", debido a que connotan un grupo de reglas persistentes y conectadas que prescriben el comportamiento, constriñen la actividad y moldean las expectativas de los actores que pertenecen al sistema. En pocas palabras, establecen las "reglas del juego". De igual manera, moldean el nivel de cooperación y, muy probablemente, definen las posibilidades en relación con el éxito o fracaso de los regionalismos (pp. 200-230). Cabe resaltar que las instituciones, al ser parte del proceso dinámico de los regionalismos, regulan el comportamiento de los Estados vis-á-vis la normatividad establecida en los tratados constitutivos. Aunado a lo anterior, supervisan el escenario para que los Estados actúen de manera recíproca, haciendo racionales sus interacciones.

Finalmente, la teoría de la seguridad compleja de la Escuela de Copenhague afirma que las integraciones regionales contribuyen a resolver los problemas de seguridad no tradiciones y de carácter transfronterizo que enfrentan los Estados en el actual orden internacional. Cabe hacer alusión a que esta teoría fue creada al finalizar la Guerra Fría, y sus premisas hacen alusión a que los nuevos 
problemas de seguridad que enfrentan los Estados ya no provienen de los riesgos tradiciones que históricamente enfrentaban, como por ejemplo una guerra. Así las cosas, la teoría de la seguridad compleja alude a que la esencia de los nuevos problemas de seguridad hoy en día tiene sus orígenes en las problemáticas transfronterizas, tales como: la migración indocumentada, la trata de personas, el crimen organizado, la venta ilegal de armamentos, las epidemias, el terrorismo, los problemas medioambientales, el fanatismo religioso, la inestabilidad política, o bien, los Estados autoritarios, totalitarios o los sistemas políticos populistas (Politi, 1997, pp. 2-10).

\section{EL SURGIMIENTO DE LA PRIMERA OLA DE REGIONALISMOS}

Desde la perspectiva de Fred Halliday (1983), durante la Guerra Fría, la gran mayoría de los regionalismos estuvieron sensiblemente subordinados a la confrontación entre Estados Unidos y la otrora urss. En este sentido, una cantidad considerable de los regionalismos de la "era bipolar" no respondían a los intereses de los miembros que los conformaban y, por consiguiente, predominaban los intereses hegemónicos de las dos exsuperpotencias mundiales. Un ejemplo empírico sobre la naturaleza de dichos regionalismos lo constituyeron el Pacto de Varsovia (pv) el Consejo de Ayuda Mutua Económica (CAME), la Or- ganización de Estados Americanos (OEA), la Organización del Tratado del Sudeste Asiático (OTSA), la Organización del Tratado Central (отс), el Tratado Interamericano de Asistencia Recíproca, así como la Organización del Tratado del Atlántico Norte (OTAN) (Bernatowicz, 1994, pp. 27-32). En todas las organizaciones anteriormente mencionadas, Estados Unidos y la otrora URSS se caracterizaron por ser los actores hegemónicos, y los "aliados" fueron miembros periféricos que no tenían mayor poder para transformar el sistema.

Aunque algunos de los regionalismos de la época de la Guerra Fría poseían una amplía institucionalización, respondían en su gran mayoría a la teoría que postula Karl W. Deutsch inherente al juego de suma cero. Sin lugar a dudas, este fenómeno fue más palpable en Europa del Este, en donde la URSs, por medio del uso de la fuerza, la intimidación, así como de la utilización de la Doctrina Brézhnev², subordinó a todos sus países exsatélites a los regionalismos que fueron creados in situ después de 1945 (Halliday,1983, pp. 58-63 ).

Ahora bien, no todos los regionalismos que fueron creados durante la Guerra Fría respondieron a su lógica. En este sentido, surgieron algunas integraciones regionales en América Latina y África cuyo objetivo fue impulsar el desarrollo interno de los Estados, la industrialización y terminar con lo que aquellos años se consideraba como la dependencia histórica: "centro-periferia".

\footnotetext{
2 Desde la perspectiva de Alberto Rocha Valencia, las potencias medias son países que se sitúan en la parte intermedia de la jerarquía del poder mundial que, por lo general, poseen una gran influencia en sus respectivos continentes. Para mayor información véase Rocha y Morales (2011, p. 34).
} 
Entre las integraciones regionales más importantes que surgieron durante la primera ola de la regionalización mundial resaltan: la Asociación Latinoamericana de Libre Comercio (Alalc, 1960), el Pacto Andino (PA, 1969), la Asociación de Libre Comercio del Caribe (CARIFTA, 1967), la Asociación Europea de Libre Comercio (AELC, 1960), la Asociación de Naciones del Sureste Asiático (ansea, 1967), el Mercado Común Centroamericano (MCCA, 1960), el Mercado Común Árabe (MCA, 1964), la Unión Económica y Aduanera de África Central (UEAAC, 1964), la Asociación Europea de Libre Comercio (AELC, 1960), el Consejo de Ayuda Mutua Económica (1949), las Comunidades Económicas Europeas (1957), y el Sistema Económico Latinoamericano (SELA) (Bernatowicz, 1994, pp. 27-32).

\section{LA EMERGENCIA DE LA SEGUNDA OLA DE LOS REGIONALISMOS}

El fin de la Guerra Fría, y el nuevo orden multipolar que surgió después de finalizar el conflicto Este-Oeste, contribuyeron a generar integraciones regionales muy diferentes en comparación con las que existieron en el statu quo ante. En este sentido, los regionalismos de la segunda ola han estado fuertemente influenciados por las siguientes variables: el fin del orden bipolar; la tercera ola de la democratización mundial que tuvo efecto en Amé- rica, África, Asia y Europa del Este; las nuevas problemáticas transfronterizas, así como el incremento de la competitividad económica de las regiones (Rodríguez, 2013, pp. 18-19).

Por otro lado, la pérdida de la hegemonía de Estados Unidos y de Europa Occidental en muchas esferas del poder mundial, como en la economía, la ciencia y la tecnología, así como el surgimiento de lo que Alberto Rocha Valencia y Daniel Efrén (2011) denominan: "las potencias mundiales, medias y regionales" 3 , ha contribuido al surgimiento de la segunda ola de los regionalismos. Las potencias medias son Estados que, aunque no se constituyen como superpotencias, poseen un gran peso en las relaciones internacionales y, más aún, en las regiones en donde se encuentran ubicados, como es el caso de Alemania y Francia en Europa Occidental, Rusia en la "nueva Europa del Este", Brasil y México en América Latina, o China y Japón en Asia. En este sentido, las potencias medias intentan crear sus propios regionalismos con el fin de acentuar su poder e influencia en sus respectivas zonas de influencia.

Otro elemento adicional que caracteriza la esencia de los regionalismos de la segunda ola es que, en la mayoría de los casos, los intereses económicos prevalecen por encima de los intereses de seguridad, aunque todos ellos tienen una fuerte dosis de componentes políticos que no aparecen escritos en los tratados constitutivos.

\footnotetext{
3 Los niveles de integración comprenden: acuerdos preferenciales, libre comercio, uniones aduaneras, mercados comunes y, finalmente, la unión económica, política y monetaria. Para mayor información véase Tamames (2010, p. 32).
} 
Por otro lado, algunos especialistas como Edward Haliżak (1996), aluden a que los regionalismos de la primera y segunda ola han ayudado a algunas regiones del mundo a mejorar las relaciones de cooperación de carácter intrarregional. Asimismo, los regionalismos pueden contribuir a mantener la paz y la estabilidad en las regiones y pueden contribuir a mejorar las relaciones de cooperación entre los países que anteriormente se percibían como antagónicos o rivales históricos, tal y como lo evidencian las otrora relaciones entre Alemania y Francia, Alemania y Polonia, Argentina y Brasil, Argentina y Chile, México y Estados Unidos, Canadá y Estados Unidos o India y Pakistán, lo que demuestra empíricamente los beneficios positivos que puede generar la cooperación intrarregional.

Entre los regionalismos más importantes que surgieron a finales del siglo xx e inicios del siglo xxi resaltan: el Tratado de Libre Comercio de América del Norte (1994), El Mercado Común del Cono Sur (mercosur, 1991), el Consejo Económico Asia-Pacífico (APEC, 1989), el Área Centro Europea de Libre Comercio (aCElC, 1992), la Unión Monetaria y Económica de África Occidental (UMEAo, 1994), la Unión del Magreb Árabe (UMA, 1989), la Comunidad Económica Africana (CEA, 1991), el Mercado Común para África del Sur y Oriental (comesa, 1993), el Sistema de Integración Centroamericano (sICA, 1991), la Asociación de Estados del Caribe (AEC, 1994), la Comunidad de Estados Inde- pendientes (CEI, I99I), la Alianza Bolivariana para los Pueblos de Nuestra América (ALBA, 2014), la Comunidad de Estados Latinoamericanos y Caribeños (CELAC, 2010), el Acuerdo Transpacífico de Cooperación Económica (ATce, 2015 ), la Alianza del Pacífico (2015), así como el Acuerdo Transpacífico de Asociación Económica (тPp, 2015). Finalmente, los niveles de integración varían de acuerdo con cada tipo de regionalismo. En este sentido, algunas integraciones regionales se limitan a establecer un simple libre comercio como el TLCAN o el G-2, mientras otras pretenden edificar una federación o confederación de Estados como la UE ${ }^{4}$.

\section{LOS PROCESOS DE REGIONALIZACIÓN EN AMÉRICA LATINA Y EN AMÉRICA DEL NORTE EN EL MARCO DE LA PRIMERA Y LA SEGUNDA OLA DE LA REGIONALIZACIÓN MUNDIAL}

\section{América Latina}

Sin lugar a dudas, la integración regional de América Latina posee una larga y fuerte tradición. En efecto, muchos de los regionalismos que actualmente existen en la región tuvieron sus orígenes durante la primera ola de la regionalización mundial (1950-1960). Los regionalismos de la "primera ola" emergieron in situ debido a diferentes variables, tales como: el sentimiento de "hermandad" y "solidaridad" que siempre ha existido entre los países de la región, así como diferentes problemáticas

\footnotetext{
4 Para mayor información sobre los adjetivos que recibió México por su incorporación al TLCAN y su cobertura de TlC y asociaciones económicas con otros países véanse: O’Neil (2013), Muniz y Chias (2012, 2015).
} 
económicas que enfrentaban y aun padecen prácticamente todas las economías de la región. Otras variables no menos importantes fueron el deseo por incrementar las relaciones económicas intrarregionales, contrarrestar la dependencia centro-periferia, maximizar el peso de la región a nivel internacional, edificar un frente común hacia la hegemonía de Estados Unidos, incrementar la calidad de vida de millones de latinoamericanos, así como reducir los niveles de pobreza y de desigualdad social (Legler, 2010, pp. 2-5).

Como se mencionó, los regionalismos en América Latina-que fueron creados durante la primera y la segunda ola- no se establecieron con la finalidad de participar en la lucha ideológica Este-Oeste. Las integraciones regionales más importantes creadas durante la primera ola en América Latina fueron la Comunidad Andina (CA, 1969), la Comunidad del Caribe (CARICOM, 1973), el Mercado Común Centroamericano (MCCA, 1960), y la Comisión Económica para América Latina y el Caribe (CEPAL 1951), que aunque no representan una integración regional per se, connotan una gran herramienta en aras de propiciar la emergencia de los regionalismos durante la primera ola. En este marco de ideas, los primeros regionalismos que aparecen en América Latina durante las décadas de los cincuenta y sesenta estuvieron fuertemente inspirados en las políticas económicas de la CEPAL, así como en la teoría de la dependencia de Raúl Prebisch y Singer.

Es importante mencionar que durante las décadas de los cincuenta, sesenta y setenta el crecimiento, el desarrollo y la importancia de las economías de la región eran muy modestas.
Por otro lado, se consideraba que los mercados internos de los países latinoamericanos eran muy pequeños para que el modelo de sustitución de importaciones (MSI) tuviera éxito, por lo que algunos economistas como Raúl Prebisch (2012) eran de la opinión de que la dimensión tan modesta de dichos mercados imposibilitaba los procesos de industrialización. Cabe hacer alusión a que el MSI tenía como objetivo la industrialización de la mayoría de las economías de la región, por medio del desarrollo interno, así como por un fuerte proteccionismo vis-á-vis los intercambios económicos internacionales. En realidad, las economías latinoamericanas que se incorporaron al MSI estaban fuertemente controladas por el Estado, y un gran número de empresas pertenecía al sector gubernamental. Los regionalismos de América Latina durante estos años pretendían eliminar las barreras comerciales a la inversión extranjera entre los países que pertenecían al "sistema integrado". Asimismo, se intentó establecer de manera conjunta la protección comercial vis-á-vis terceros países. Aunado a lo anterior, existió el deseo de establecer un fuerte aparato institucional cuyo objetivo era la institucionalización de la integración de América Latina, fuertemente inspirado en el de las instituciones de la CEE.

Los regionalismos latinoamericanos que fueron creados durante la primera ola tuvieron los siguientes objetivos:

- Reducir la dependencia extranjera por medio de un alto nivel de proteccionismo.

- La fuerte participación del Estado.

- Complementar las limitaciones del msi por medio de la desviación de las impor- 
taciones de terceros países hacia la producción y la exportación intrarregional.

- No depender del comercio internacional. En efecto, se consideraba al comercio internacional y al neoliberalismo como variables que acentuaban la dependencia centro-periferia.

Para finales de la década de los ochenta, el MSI se encontraba prácticamente agotado, la participación del Estado fue excesiva y altamente proteccionista. Asimismo, las empresas paraestatales se caracterizaban por ser poco competitivas y muchas de ellas eran obsoletas. Aunado a lo anterior, muchos de los sindicatos cuya tarea era la de "proteger los derechos y los intereses de los trabajadores", se convirtieron en fuertes herramientas políticas al servicio del poder estatal. En el caso de México, a este tipo de sindicatos se les denominó "los sindicatos charros". Asimismo, las dictaduras en un considerable número de países de América del Sur, los regímenes autoritarios como el de México y el gran proteccionismo hacia el comercio internacional, tuvieron como consecuencia que los regionalismos latinoamericanos tuvieran pocos resultados tangibles hacia la integración e industrialización de América Latina.

Otro impedimento hacia la evolución positiva de los regionalismos latinoamericanos fue que todas las economías de la región se constituían en aquellos ańos como proveedoras de materias primas y continuaban importando del "centro" prácticamente toda la tecnología que utilizaban, por lo que el ideal de cortar de lleno con la dependencia del "centro" se quedó en un simple deseo.

\section{La segunda ola de los regionalismos latinoamericanos: 1980-2016}

Durante las décadas de los ochenta y noventa surgió en el escenario internacional la "segunda ola de regionalismos". Aunque ha sido un fenómeno mundial, América Latina se ha caracterizado por ser un actor muy activo y dinámico. En este sentido, se trataron de reactivar algunas integraciones regionales que surgieron durante la primera ola y fueron creados nuevos regionalismos de carácter bilateral, trilateral y multilateral.

El surgimiento de la segunda ola de regionalismos en América Latina tuvo sus orígenes en variables internas y externas. En relación con las internas, el fin del Msi, la incorporación al sistema económico neoliberal de la mayoría de las economías de la región y la necesidad de ampliar los mercados han jugado un papel central. Asimismo, América Latina entró a una nueva fase política al finalizar los regímenes totalitarios y autoritarios. En cuanto a las variables externas, los países de América Latina abrieron sus mercados a la economía internacional, se integraron plenamente a la globalización y percibieron el fenómeno de la integración como una herramienta que contribuiría a combatir las problemáticas históricas que hasta el día de hoy impactan la región.

Cabe mencionar que las siguientes iniciativas fueron creadas en aras de reactivar algunos regionalismos latinoamericanos: el Plan de Acción Económica para Centroamérica, en el contexto del Mercado Común Centroamericano (MCCA) en 1990; el Protocolo de Tegucigalpa, que estableció el Sistema de Integración Centroamericana (sICA) en 1991; 
el fortalecimiento de la integración andina mediante el Pacto Andino desde 1991; el Protocolo de Trujillo, en 1996, y el Protocolo de Sucre, en 1997, que finalmente transformaron el Pacto Andino en Comunidad Andina en 1997. Asimismo, se llevó a cabo la firma de numerosos acuerdos de complementación económica en el marco de la Asociación Latinoamericana de Integración (ALADI) durante los años noventa.

Aunado a lo anterior, una cantidad muy considerable de integraciones bilaterales, trilaterales y multilaterales fueron establecidas. Entre las más importantes resaltan: el Grupo de los Tres (G-3) entre Colombia, México y Venezuela en 1990; el ALBA, el Mercado Común del Sur en 1991, la Asociación de Estados del Caribe (AEC) en 1994, la CELAC en el 2010, el TLCAN en 1994 y la Comunidad de Estados Latinoamericanos y Caribeños en el 2010, así como la Alianza del Pacífico en el 2011.

Los regionalismos que nacieron durante la segunda ola en América Latina y el Caribe se caracterizan por su enorme diversidad y heterogeneidad. Desde la perspectiva de Josep Ibáńez (2015), dichos regionalismos pueden ser diferenciados de la siguiente manera:

1. Diversidad. La diversidad de los regionalismos en América Latina puede ser definida de acuerdo con los objetivos, alcances, niveles de institucionalización, así como por el nivel de participación del Estado. Cabe mencionar que a pesar de las enormes diferencias que existen entre dichas integraciones regionales, el objetivo cardinal es la integración económica, pero de manera diferente. Otra diferencia es que mientras algunas integraciones regionales constituyen solo áreas de libre comercio, otras han ido mucho más lejos con la edificación de mercados comunes que incluso promueven una fuerte movilidad de personas, bienes capitales y servicios.

2. Institucionalidad. En algunos regionalismos de la región el nivel de institucionalización es muy endeble, mientras en otros es relativamente alto, tal y como lo ejemplifica el actual G-2 y el MERCOSUR, o bien, la Alianza del Pacífico.

3. Participación del Estado. Otra diferencia de las integraciones regionales en América Latina puede ser identificada por medio del nivel de la participación del Estado, así como por los objetivos y los alcances gubernamentales.

4. Alcances. Aunque en su gran mayoría los regionalismos de América Latina lo que pretenden es la integración económi$\mathrm{ca}$, también existen algunos que poseen un alto componente político, o incluso incorporan al populismo como su base ideológica, tal y como lo ejemplifica el caso del alba. Por otro lado, algunos regionalismos tan solo buscan la integración económica en el marco de un área de libre comercio, mientras otros desean ir más allá con la formación de una unión aduanera.

\section{AmÉRICA Del Norte y SU INTEgRACIÓN REgIONAL}

La integración regional de América del Norte nace en el contexto de la segunda ola de regionalismos. El punto de partida fue el Tratado 
de Libre Comercio firmado entre Canadá y Estados Unidos el 4 de octubre de 1988, mejor conocido como cusFTa por sus siglas en inglés. Posteriormente, en 1991, Estados Unidos y México decidieron establecer su propio TLC. Canadá, ante el temor de quedar excluida, decidió participar en las negociaciones, que concluyeron en 1994, creando el TLCAN, que en aquellos años constituyó el área de libre comercio más grande del mundo.

Sin duda alguna, durante el fin del siglo $\mathrm{xx}$ existieron variables internas y externas que impulsaron el surgimiento de la integración económica en América del Norte. Entre las variables internas, los tres países deseaban ampliar sus mercados, incrementar su competitividad e institucionalizar su integración económica regional. En el caso particular de México, se esperaba que el TLCAN impulsara las reformas internas que se estaban gestando en el país, que transformarían radicalmente al sistema económico, político y social de México.

Entre las variables externas, Estados Unidos deseó profundizar sus relaciones económicas con Canadá y México. Asimismo, enfrentaba una gran competencia vis-á-vis algunos actores internacionales, principalmente de la UE, Japón y China. En relación con Canadá, Ottawa no quiso perder su mercado más importante que es el de Estados Unidos y quedar excluida del proceso de integración que se estaba gestando entre Estados Unidos y México. En cuanto al caso de México, este país consideró que al finalizar el MSI, gran parte de su desarrollo sería impulsado por la cercanía geográfica que posee frente a dos de las economías más desarrolladas del mundo. Otras de las variables externas que influyeron sensiblemente ante la edificación del TLCAN fueron el fortalecimiento de la integración europea y, sobre todo, su ampliación hacia Europa del Este. Asimismo, se intentó fortalecer el proceso de inserción de la economía mexicana en el comercio internacional, incrementar el peso de negociación ante otras economías desarrolladas y emergentes del mundo, así como convertir a México en "la puerta de entrada y salida" del comercio internacional hacia América del Norte y América Latina.

Los objetivos escritos en el tratado constitutivo del TLCAN fueron los siguientes:

- Eliminar las barreras comerciales al comercio trilateral.

- Promover las condiciones para una competencia justa e incrementar las oportunidades de inversión en América del Norte.

- Establecer procedimientos efectivos para la aplicación del tratado y la solución de controversias.

- Fomentar la cooperación trilateral y regional.

Los objetivos no escritos en el tratado, pero que a todas luces fueron claros para los tres países durante las negociaciones del TLCAN, fueron los siguientes:

- Promover el desarrollo de la economía mexicana con la finalidad de reducir la migración indocumentada de mexicanos hacia Estados Unidos.

- Incrementar el peso y la competitividad de Estados Unidos y América del Norte en la economía internacional. 
- Crear el área de libre comercio más grande del mundo.

- Transformar radicalmente las relaciones políticas entre Estados Unidos y México, caracterizadas a través de la historia como "porosas".

- Integrar a México al nivel de desarrollo de Estados Unidos y Canadá.

- Convertir a América del Norte en la región más competitiva del mundo.

- El trcan sería la antesala del Área de Libre Comercio de las Américas (ALCA).

- América del Norte se convertiría en uno de los tres centros del poder económico mundial. $\mathrm{O}$ en lo que denomina el economista japonés Kenichi Ohmae (1985) como la "triada económica mundial", en donde circula el $80 \%$ del comercio internacional. Dicha triada comprende a América del Norte, Europa Occidental y Asia.

\section{LOS RESULTADOS DEL TLCAN DESDE LA PERSPECTIVA DE MÉXICO}

Un considerable número de especialistas mexicanos, como Jorge Castañeda (2014), son de la opinión de que el TLCAN ha contribuido a profundizar e incluso a triplicar el comercio intrarregional entre los tres países de América del Norte, en particular entre México y
Estados Unidos, y en menor medida entre Canadá y México. Asimismo, ha fortalecido el poder de negociación de México vis-á-vis otras economías del mundo, por consiguiente, fue considerado a principios del siglo XXI como "la economía del mundo que más tratados de libre comercio y asociaciones económicas poseía en el escenario internacional". Otros adjetivos fueron también añadidos como "el momento de México", "el milagro mexicano" y "México lo logra", por los medios de comunicación más influyentes del mundo, tales como The New York Times, The Washington Post, así como por las prestigiosas revistas The Economist, Foreign Affairs y el bcg.perspectives ${ }^{5}$.

Aunado a lo anterior, la economía mexicana se transformó radicalmente. De ser una economía totalmente periférica durante prácticamente todo el siglo $\mathrm{xx}$, se convirtió en la número 14 a nivel mundial según el Fondo Monetario Internacional (FMI) y el Banco Mundial (вм), así como en la cuarta más grande de América, después de Estados Unidos, Canadá y Brasil. Asimismo, hoy en día constituye el primer exportador e importador de bienes y servicios de América Latina. Aunado a lo anterior, durante la década de los noventa México se convirtió en la segunda economía emergente que más IED recibió de los mercados internacionales después de China.

\footnotetext{
5 La Doctrina Brezhnev -o "Doctrina de soberanía limitada" - fue una doctrina de política exterior de la otrora URSs. Dicha doctrina fue introducida por Leonid Brezhnev en 1968. En suma, establecía que ningún país del bloque socialista podría abandonar el sistema socialista de Europa del Este liderado por la uRss. Esta doctrina se utilizó para justificar las intervenciones militares del Pacto de Varsovia en Hungría, en 1956, y en Checoslovaquia, en 1968. Estas invasiones fueron justificadas por la URSS y los miembros del Pacto de Varsovia como: "acciones preventivas y de ayuda a países hermanos en donde las fuerzas externas amenazaban al socialismo real" (Lara, 2015).
} 
En este mismo orden de ideas, antes del TLCAN México era un socio económico periférico de Estados Unidos, posteriormente se convirtió en el segundo socio comercial más importante para la economía estadounidense. En cuanto a México y Canadá, ambos países constituyen sus terceros socios económicos más importantes. En relación con el incremento del poder de negociación de México, este país fue el primero de América Latina en convertirse en Miembro de la Organización para la Cooperación y el Desarrollo Económicos (OCDE) en 1994, el único país de América Latina en formar parte como miembro permanente del Banco Europeo para la Reconstrucción y el Desarrollo Económico en 1991, y fue el primer país de América Latina en subscribir con la ue un Acuerdo de Asociación Económica, Concertación Política y Cooperación, en 1997. Asimismo, se convirtió en miembro del Foro de Cooperación Económica Asia-Pacífico en 1993, y estableció un número considerable de TLC con diversos países del mundo, tales como: Israel, Japón, la Asociación Europea de libre Comercio y con prácticamente con todos los países de América Latina y el Caribe.

En cuanto a América del Norte, como se aludió con anterioridad, las exportaciones mexicanas hacia Estados Unidos se triplicaron; por citar un ejemplo, en 1994 constituían 60.000 millones de dólares (año en que el TLCAN entró en vigor), para el año 2014, dichos indicadores se transformaron en casi 400.000 millones de dólares (TlCanHoy, 2015). Por otro lado, México se convirtió en el tercer socio comercial más importante para Canadá. Cabe mencionar que, antes del
TLCAN, figuraba como su decimotercer socio comercial. Aunque el comercio bilateral entre ambos países se ha incrementado en 8,4 veces, todavía está muy lejos de crecer de manera similar en comparación con el de Estados Unidos y México.

Debido al gran incremento del comercio exterior con América del Norte y la apertura de la economía mexicana hacia el mundo, millones de mexicanos se han visto beneficiados; así, actualmente millones de mexicanos tienen acceso a bienes y servicios que anteriormente solo podían ser adquiridos por una clase social privilegiada, que constituía tan solo la tercera parte de la población. Por otro lado, la integración con América del Norte y la apertura de la economía mexicana han contribuido a transformar a la sociedad mexicana, en particular a la clase media. En términos políticos el TLCAN, así como el cambio radical de la política exterior de Estados Unidos hacia México han ayudado a terminar con el sentimiento de "victimización" que ha mantenido México hacia su vecino del norte por siglos. Sin embargo, aún hay muchos retos que contrarrestar, tales como: el cambio de actitud de algunos partidos políticos en México y en toda América del Norte para finalizar con los estereotipos históricos que prevalecen en toda la región que tanto afectan a la cooperación trilateral. Otros retos no menos importantes son: terminar con el temor histórico mexicano en relación con la pérdida de la "soberanía" debido a la integración con Estados Unidos y Canadá; incrementar la participación de la sociedad civil, de los medios de comunicación, de la IP, así como de las universidades e instituciones de investigación en relación con 
la construcción de la integración de América del Norte.

Finalmente, México enfrenta un gran desafío ante Estados Unidos y Canadá debido a que debe de iniciar una gran campaña política y cultural vis-á-vis sus vecinos del norte en relación con los grandes beneficios que puede acarrear la profundización de la integración de América del Norte. Sin lugar a dudas, esta tarea no será nada fácil

Otros retos mayúsculos que enfrenta México son: convencer a Estados Unidos y Canadá de los grandes beneficios que podrían obtenerse con la profundización de la integración regional, tarea que desde luego no será nada fácil debido a los prejuicios tradicionales, los estereotipos, las rivalidades, así como por las enormes asimetrías que existen entre las economías de Estados Unidos, Canadá y México. Indudablemente, esta tarea no será nada fácil pero tampoco es imposible, tal y como lo han demostrado los países de Europa del Este cuando al finalizar la Guerra Fría intentaban obtener por todos los medios posibles la membresía de la UE y de la OTAN, que finalmente lograron cuando ingresaron en ambos organismos a finales del siglo xx e inicios del XXI.

\section{Las promesas no cumplidas del TLCAN}

Muchos de los tan esperados beneficios y promesas que se esperaban con tanto entusiasmo en México antes de ser suscrito el TLCAN, continúan sin cumplirse. Entre estas promesas resaltan: la transformación plena de la economía mexicana en relación con el fin de los oligopolios en las telecomunica- ciones, la reducción de la pobreza, convertir a México en un país desarrollado, así como terminar con los problemas históricos de este país, tales como: la corrupción, la impunidad, el endeble apego al Estado de derecho, la deficiente calidad de la educación pública, así como, el fortalecimiento de las instituciones gubernamentales. En este marco de ideas, se esperaba que amén del TLCAN la economía mexicana se transformaría en una economía del primer mundo; sin embargo, esto nunca llegó y actualmente 45 millones de mexicanos son considerados como pobres, y aunque el país ha dado pasos significativos en cuanto a su crecimiento económico, la pobreza continúa incrementándose. Sin embargo, habría que preguntarse si este fenómeno responde a las deficiencias del TLCAN o si es inherente a las problemáticas históricas del país anteriormente mencionadas.

Aunado a lo anterior, el crecimiento del PIB ha estado muy por debajo en comparación con otras economías emergentes debido a que este ha alcanzado tan solo el 2,6\%. Lo mismo ha sucedido con el crecimiento del pIB per cápita, que ha sido inferior al de otras economías emergentes tales como: Brasil Chile, Colombia, Perú, Uruguay y de prácticamente de todos los nuevos miembros de la UE de Europa del Este. En materia de desarrollo científico y tecnológico, la inversión gubernamental es realmente efímera y la élite gubernamental aún está muy lejos de percibir a la ciencia y a la tecnología como una herramienta sine die para el desarrollo del país. Por otro lado, las instituciones que posee el TLCAN son muy endebles, y en la gran mayoría de dichas instituciones solo participan Estados Unidos 
y México, mientras que la participación de Canadá es sumamente limitada (Clarkson, 2009, pp. 85-89). Aunado a lo anterior, los tres países de América del Norte invierten poco capital económico y político para fortalecer y ampliar el aparato institucional del TLCAN, tal y como lo ejemplifica el caso del Banco Norteamericano de Desarrollo ${ }^{6}$.

\section{CONCLUSIONES}

Sin duda alguna, los regionalismos del statu quo ante fueron radicalmente diferentes a los que existen en el actual statu quo. Aquellos que nacieron durante la primera ola, en su gran mayoría fueron creados desde la perspectiva de la lucha ideológica Este-Oeste. En este sentido, la gran mayoría de las agrupaciones regionales se edificaron desde la óptica de la teoría del juego de suma cero que postula Karl W. Deustch. En suma, prevalecían los intereses y la hegemonía de Estados Unidos y de la urss, en detrimento de los países periféricos que tenían poco poder para modificar el sistema.

Sin embargo, otros regionalismos que fueron creados durante la primera ola, como los que emergieron en América Latina y África, no tuvieron como objetivo participar en la confrontación bipolar Este-Oeste. En este sentido, los objetivos de los regionalismos latinoamericanos fueron los siguientes: promover la integración económica entre los países de la región, impulsar el desarrollo, la industrialización y, sobre todo, finalizar con la dependencia centro-periferia. Cabe mencionar que estos regionalismos fueron creados bajo el liderazgo de la CEPAL, así como de las premisas de la teoría de Raúl Prebisch Singer, mejor conocida como la Teoría de la Dependencia.

Los regionalismos latinoamericanos de la primera ola no alcanzaron mayores objetivos. Probablemente, el poco éxito que obtuvieron responde a diferentes variables. En este contexto, las economías de la región estaban fuertemente protegidas por el Estado y no estaban completamente abiertas al comercio internacional. Asimismo, todas estas economías se caracterizaban por producir bienes primarios y no existían una o dos economías desarrolladas que se constituyeran como "el motor de la integración latinoamericana”. Por otro lado, el sistema político que imperó en la región durante estos años contribuyó muy poco a incrementar el comercio y la industrialización in situ.

Por otro lado, los regionalismos de la segunda ola nacen a finales de la década de los ochenta y continúan proliferándose hasta nuestros días. Entre las diferencias que se pueden observar entre los regionalismos de la primera y de la segunda ola, se encuentra que, como se aludió con anterioridad, los nuevos regionalismos nacen por intereses económicos y no por confrontaciones ideológicas, aunque también poseen una fuerte dosis de intereses políticos y de seguridad.

\footnotetext{
6 Las instituciones del trCan son: la Comisión de Libre Comercio, el Grupo de coordinadores del TLCAN, los Grupos de trabajo y los Comités del trCan, el Secretariado del trCan, la Comisión para la Cooperación Laboral, la Comisión para la Cooperación Ambiental y el Banco Norteamericano de Desarrollo. Para mayor información en relación con las instituciones del TLCAN véase: http://www.tlcanhoy.org/about/default_es.asp
} 
Otras características de los regionalismos de la segunda ola es que, en primera instancia, son las iniciativas gubernamentales quienes por lo general edifican los regionalismos y posteriormente intervienen otros actores, tales como: la sociedad civil, las organizaciones no gubernamentales, las empresas transnacionales, las universidades y las instituciones de investigación. Por otro lado, resulta muy difícil conceptualizar teóricamente a todos los regionalismos de la segunda ola debido a sus enormes diferencias en términos de sus objetivos y sus alcances. Los TLC son creados desde la perspectiva del juego de suma cero, otros regionalismos nacen desde la óptica del juego de suma variable y otros desde la visión de la teoría de la seguridad compleja. Asimismo, algunos regionalismos están fuertemente inspirados en la teoría neoinstitucional.

Sin duda alguna, los regionalismos constituyen uno de los temas más importantes de la agenda de las relaciones internacionales del siglo XXI y pueden connotar una herramienta de desarrollo muy importante para los países emergentes debido a que eliminan el aislacionismo económico, profundizan las relaciones de cooperación, incrementan el peso de las regiones en el escenario internacional, así como la calidad de vida las personas. Aunado a lo anterior, contribuyen a confrontar las nuevas problemáticas transfronterizas que afectan a los Estados en el siglo xxI, tal y como lo postula la teoría de la seguridad compleja.

Los regionalismos en donde los resultados han sido menos exitosos, frecuentemente carecen de un gran acompañamiento institucional, como ha sido el caso de un gran número de integraciones regionales de América Latina y de América del Norte. En relación con América Latina, desde la primera ola de los regionalismos hasta nuestros días, la construcción de las integraciones regionales ha sido un proceso activo y constante. Sin embargo, los resultados han sido muy endebles y una cantidad considerable de integraciones regionales se han quedado en los buenos deseos. Otra problemática muy importante es que los Estados latinoamericanos invierten poco capital político y, sobre todo, económico en aras de que los regionalismos de la región prosperen, evolucionen y sean exitosos. En este sentido, desde la visión de la teoría neoinstitucional de Sven Steinmo, muchos de estos regionalismos fracasan al no estar plenamente acompañados por un buen sistema institucional.

En América del Norte, aunque las relaciones económicas se han triplicado entre Estados Unidos y México, y han crecido notoriamente los intercambios comerciales entre Canadá y México, y a pesar del éxito que ha tenido dicha integración en términos económicos, los beneficios han sido en su gran mayoría para las empresas transnacionales, y las clases altas y medias, y no ha contribuido a erradicar las problemáticas históricas de México.

El panorama expuesto en este artículo nos obliga a reflexionar en torno a los regionalismos del siglo xxI, en particular en América del Norte y en América Latina, así como en sus logros, debilidades y, en particular, en relación con los enormes retos que enfrentan. Asimismo, nos invita a reflexionar sobre las variables que han propiciado que algunos regionalismos, tanto de América del Norte como de América Latina, sean exitosos, mientras otros permanecen en el olvido. 
Sin duda alguna, la fortaleza y los buenos resultados de los regionalismos dependen no solo de la evolución de la economía mundial, la revolución tecnológica, la globalización, así como del incremento del comercio intrarregional y de la aplicación de indicadores neoliberales, que solo permiten observar los resultados de las integraciones regionales por medio del incremento de las relaciones económicas.

En este sentido, los indicadores que se utilizan generalmente como barómetros para medir los resultados de los regionalismos no deben de proporcionar tan solo cifras económicas inherentes al incremento del comercio intrarregional, sino que también deben suministrar información en relación con el impacto de los regionalismos en el desarrollo de los países. Cabe subrayar que no es lo mismo crecimiento económico y desarrollo. En efecto, muchos países crecen económicamente pero no logran efectuar grandes avances en términos de su desarrollo desde una perspectiva social, económica y política e incluso cultural.

Aunque los regionalismos de América del Norte y de América Latina han contribuido a incrementar las relaciones económicas entre sus miembros, poco han hecho para para erradicar la pobreza, las desigualdades sociales y consolidar la democracia, así como para fortalecer las instituciones políticas y terminar con problemáticas históricas inherentes a la impunidad, la corrupción y el poco apego al Estado de derecho. Otros retos que enfrentan las integraciones regionales del continente americano son los de propiciar la libre movilidad de las personas (estudiantes, académicos, investigadores y empresarios), y profundizar la identidad regional, que sin duda contribuirá a incrementar las relaciones económicas, mejorar las relaciones políticas, dirimir los diferendos regionales y confrontar los nuevos problemas de seguridad transfronterizos que enfrentan todos los Estados que comprenden América del Norte y América Latina.

\section{REFERENCIAS}

Bernatowicz, G. (1994). Europe of regions. The Polish Quarterly of International Affairs, 27-32.

Clarkson, S. (2009). ¿Existe una América del Norte? Revista Mexicana de Politica Exterior, 85-89.

Castañeda, J. (2014). Los claroscuros del tLCan: el panorama desde México. Recuperado de http:// www.cva.itesm.mx/biblioteca/pagina_con_formato_version_oct/apaweb.html

Deustch, K. (1994). Análisis de las relaciones internacionales. Ciudad de México: Gernika.

Halizak, E. (1996). Regionalism in International Relations. The Polish Quarterly of International Affairs, 220-228.

Halliday, F. (1983). The Making of the Second Cold War. London: Verso.

Ibáńez, J. (2015). El nuevo regionalismo latinoamericano en los años noventa. Recuperado de http:// www.insumisos.com/lecturasinsumisas/Nuevo\%20regionalismo\%20latinoamericano.pdf

Kenichi, O. (1985). Triade Power: The Coming Shape of Global Competition. London: Free Press.

Lara, J. M. (2015). Doctrina Brezhnev: fuentes de historia para el mundo contemporáneo. Recuperado de https://hmcontemporaneo.wordpress. com/2011/09/06/doctrina-breznev/

Legler, T. (2010). El perfil del multilateralismo latinoamericano. Foregin Affairs Latinoamérica, 3, 2-5. 
Muniz, J. y Chias, L. (2012). Mexico's moment. The Economist.

Muniz, J. y Chias, L. (2015). It is mexican moment?: preparing for inevitable comsumer boom? $\mathrm{Bcg}$ perspective.

O’Neil, S. (2013). México lo logra. Foreign Affairs.

Paz, M. (2011). Perspectivas del nuevo regionalismo latinoamericano desde el enfoque de los acuerdos "sur-norte": análisis de la experiencia mexicana. Recuperado de http://eprints.ucm.es/12075/

Prebisch, R. (2012). Raúl Prebisch y el pensamiento económico latinoamericano. Recuperado de http://prebisch.cepal.org/sites/default/files/Etapas_pensamiento_Prebisch.pdf

Peters, G. (2003). El nuevo institucionalismo: la teoría de la ciencia política. Barcelona: Gedisa.

Politi, A. (1997). Nouveaux Risques Transnationaux et Securite Europeenne. Cahiers de Chaillot, 23 (46), 38-40.

Rodríguez, P. (2006). Hacia una Nueva Europa: la integración de los paises de Europa Central y Oriental en la Unión Europea. México: Fondo de Cultura Económica.
Rocha, V. y Etrén D. (2011). Potencias medias y potencias regionales en el sistema politico internacional de Guerra Fría. Propuesta de dos modelos teóricos. México: Universidad de Guadalajara.

Rodríguez, P. (2013). El fenómeno de la regionalización mundial durante los siglos xx y xxI. En Tendencias hacia la regionalización mundial en el ámbito del siglo XXI (pp. 23-27). México: BUAP.

Steinmo, S. (2009). The Evolution of Modern States: Sweden, Japan, and the United States. London: Cambridge Studies in Comparative Politics.

Tamames, R. (2010). Estructura económica mundial. Barcelona: Alianza Editorial.

TLCANHOY (2015). Resultados: los habitantes de América del Norte disfrutan de mayores beneficios tras 15 años del TLCAN. Recuperado de http://www. tlcanhoy.org/results/default_es.asp

Valencia, A. y Efrén, D. (2011). Potencias medias, potencias regionales en el sistema politico internacional de la Guerra Fría y Posguerra Fría: propuesta de dos modelos teóricos. México: Cucsh-UdeG. 